Research Article

\title{
Strong Convergence Theorems for Modifying Halpern Iterations for Quasi- $\phi$-Asymptotically Nonexpansive Multivalued Mapping in Banach Spaces with Applications
}

\author{
Li Yi \\ School of Science, Southwest University of Science and Technology, Mianyang, Sichuan 621010, China \\ Correspondence should be addressed to Li Yi, liyi@swust.edu.cn \\ Received 20 August 2012; Accepted 21 November 2012 \\ Academic Editor: Nan-Jing Huang \\ Copyright (C) $2012 \mathrm{Li}$ Yi. This is an open access article distributed under the Creative Commons \\ Attribution License, which permits unrestricted use, distribution, and reproduction in any \\ medium, provided the original work is properly cited. \\ An iterative sequence for quasi- $\phi$-asymptotically nonexpansive multivalued mapping for modify- \\ ing Halpern's iterations is introduced. Under suitable conditions, some strong convergence theo- \\ rems are proved. The results presented in the paper improve and extend the corresponding results \\ in the work by Chang et al. 2011.
}

\section{Introduction}

Throughout this paper, we denote by $N$ and $R$ the sets of positive integers and real numbers, respectively. Let $D$ be a nonempty closed subset of a real Banach space $X$. A mapping $T$ : $D \rightarrow D$ is said to be nonexpansive, if $\|T x-T y\| \leq\|x-y\|$, for all $x, y \in D$. Let $N(D)$ and $\mathrm{CB}(D)$ denote the family of nonempty subsets and nonempty closed bounded subsets of $D$, respectively. The Hausdorff metric on $\mathrm{CB}(D)$ is defined by

$$
H\left(A_{1}, A_{2}\right)=\max \left\{\sup _{x \in A_{1}} d\left(x, A_{2}\right), \sup _{y \in A_{2}} d\left(y, A_{1}\right)\right\}
$$

for $A_{1}, A_{2} \in \mathrm{CB}(D)$, where $d\left(x, A_{1}\right)=\inf \left\{\|x-y\|, y \in A_{1}\right\}$. The multivalued mapping $T$ : $D \rightarrow \mathrm{CB}(D)$ is called nonexpansive, if $H(T x, T y) \leq\|x-y\|$, for all $x, y \in D$. An element $p \in D$ is called a fixed point of $T: D \rightarrow N(D)$, if $p \in T(p)$. The set of fixed points of $T$ is represented by $F(T)$. 
Let $X$ be a real Banach space with dual $X^{*}$. We denote by $J$ the normalized duality mapping from $X$ to $2^{X^{*}}$ which is defined by

$$
J(x)=\left\{x^{*} \in X^{*}:\left\langle x, x^{*}\right\rangle=\|x\|^{2}=\left\|x^{*}\right\|^{2}\right\}, \quad x \in X
$$

where $\langle\cdot, \cdot\rangle$ denotes the generalized duality pairing.

A Banach space $X$ is said to be strictly convex, if $\|(x+y) / 2\| \leq 1$ for all $x, y \in X$ with $\|x\|=\|y\|=1$ and $x \neq y$. A Banach space is said to be uniformly convex, if $\lim _{n \rightarrow \infty}\left\|x_{n}-y_{n}\right\|=0$ for any two sequences $\left\{x_{n}\right\},\left\{y_{n}\right\} \subset X$ with $\left\|x_{n}\right\|=\left\|y_{n}\right\|=1$ and $\lim _{n \rightarrow \infty}\left\|\left(x_{n}+y_{n}\right) / 2\right\|=0$. the limit

The norm of Banach space $X$ is said to be Gateaux differentiable, if for each $x, y \in S(x)$,

$$
\lim _{t \rightarrow 0} \frac{\|x+t y\|-\|x\|}{t}
$$

exists, where $S(x)=\{x:\|x\|=1, x \in X\}$. In this case, $X$ is said to be smooth. The norm of Banach space $X$ is said to be Fréchet differentiable, if for each $x \in S(x)$, the limit (1.3) is attained uniformly, for $y \in S(x)$, and the norm is uniformly Fréchet differentiable if the limit (1.3) is attained uniformly for $x, y \in S(x)$. In this case, $X$ is said to be uniformly smooth.

Remark 1.1. The following basic properties for Banach space $X$ and for the normalized duality mapping $J$ can be found in Cioranescu [1].

(1) $X\left(X^{*}\right.$, resp. $)$ is uniformly convex if and only if $X^{*}(X$, resp.) is uniformly smooth.

(2) If $X$ is smooth, then $J$ is single-valued and norm-to-weak* continuous.

(3) If $X$ is reflexive, then $J$ is onto.

(4) If $X$ is strictly convex, then $J x \bigcap J y \neq \emptyset$, for all $x, y \in X$.

(5) If $X$ has a Fréchet differentiable norm, then $J$ is norm-to-norm continuous.

(6) If $X$ is uniformly smooth, then $J$ is uniformly norm-to-norm continuous on each bounded subset of $X$.

(7) Each uniformly convex Banach space $X$ has the Kadec-Klee property, that is, for any sequence $\left\{x_{n}\right\} \subset X$, if $x_{n} \rightarrow x \in X$ and $\left\|x_{n}\right\| \rightarrow\|x\|$, then $x_{n} \rightarrow x \in X$.

(8) If $X$ is a reflexive and strictly convex Banach space with a strictly convex dual $X^{*}$ and $J^{*}: X^{*} \rightarrow X$ is the normalized duality mapping in $X^{*}$, then $J^{-1}=J^{*}, J J^{*}=I_{X^{*}}$ and $J^{*} J=I_{X}$.

Next, we assume that $X$ is a smooth, strictly convex, and reflexive Banach space and $D$ is a nonempty, closed and convex subset of $X$. In the sequel, we always use $\phi: X \times X \rightarrow R^{+}$ to denote the Lyapunov functional defined by

$$
\phi(x, y)=\|x\|^{2}-2\langle x, J y\rangle+\|y\|^{2}, \quad x, y \in X .
$$


It is obvious from the definition of the function $\phi$ that

$$
\begin{gathered}
(\|x\|-\|y\|)^{2} \leq \phi(x, y) \leq(\|x\|+\|y\|)^{2}, \\
\phi(y, x)=\phi(y, z)+\phi(z, x)+2\langle z-y, J x-J z\rangle, \quad x, y, z \in X, \\
\phi\left(x, J^{-1}(\lambda J y+(1-\lambda) J z)\right) \leq \lambda \phi(x, y)+(1-\lambda) \phi(x, z),
\end{gathered}
$$

for all $\lambda \in[0,1]$ and $x, y, z \in X$.

Following Alber [2], the generalized projection $\Pi_{D}: X \rightarrow D$ is defined by

$$
\Pi_{D}(x)=\arg \inf _{y \in D} \phi(y, x), \quad \forall x \in X
$$

Many problems in nonlinear analysis can be reformulated as a problem of finding a fixed point of a nonexpansive mapping.

Example 1.2 (see [3]). Let $\Pi_{D}$ be the generalized projection from a smooth, reflexive and strictly convex Banach space $X$ onto a nonempty closed convex subset $D$ of $X$, then $\Pi_{D}$ is a closed and quasi- $\phi$-nonexpansive from $X$ onto $D$.

In 1953, Mann [4] introduced the following iterative sequence $\left\{x_{n}\right\}$ :

$$
x_{n+1}=\alpha_{n} x_{n}+\left(1-\alpha_{n}\right) T x_{n}
$$

where the initial guess $x_{1} \in D$ is arbitrary, and $\left\{\alpha_{n}\right\}$ is a real sequence in $[0,1]$. It is known that under appropriate settings the sequence $\left\{x_{n}\right\}$ converges weakly to a fixed point of $T$. However, even in a Hilbert space, Mann iteration may fail to converge strongly [5]. Some attempts to construct iteration method guaranteeing the strong convergence have been made. For example, Halpern [6] proposed the following so-called Halpern iteration:

$$
x_{n+1}=\alpha_{n} u+\left(1-\alpha_{n}\right) T x_{n}
$$

where $u, x_{1} \in D$ are arbitrary given and $\left\{\alpha_{n}\right\}$ is a real sequence in $[0,1]$. Another approach was proposed by Nakajo and Takahashi [7]. They generated a sequence as follows:

$$
\begin{gathered}
x_{1} \in X \text { is arbitrary, } \\
y_{n}=\alpha_{n} u+\left(1-\alpha_{n}\right) T x_{n}, \\
C_{n}=\left\{z \in D:\left\|y_{n}-z\right\| \leq\left\|x_{n}-z\right\|\right\}, \\
Q_{n}=\left\{z \in D:\left\langle x_{n}-z, x_{1}-x_{n}\right\rangle \geq 0\right\}, \\
x_{n+1}=P_{C_{n} \cap Q_{n}} x_{1} \quad(n=1,2, \ldots),
\end{gathered}
$$

where $\left\{\alpha_{n}\right\}$ is a real sequence in $[0,1]$ and $P_{K}$ denotes the metric projection from a Hilbert space $H$ onto a closed and convex subset $K$ of $H$. It should be noted here that the iteration 
previous works only in Hilbert space setting. To extend this iteration to a Banach space, the concept of relatively nonexpansive mappings are introduced (see [8-12]).

Inspired by Matsushita and Takahashi, in this paper, we introduce modifying HalpernMann iterations sequence for finding a fixed point of multivalued mapping $T: D \rightarrow \mathrm{CB}(D)$.

\section{Preliminaries}

In the sequel, we denote the strong convergence and weak convergence of the sequence $\left\{x_{n}\right\}$ by $x_{n} \rightarrow x$ and $x_{n} \rightarrow x$, respectively.

Lemma 2.1 (see [2]). Let $X$ be a smooth, strictly convex, and reflexive Banach space, and let $D$ be a nonempty closed and convex subset of $X$. Then the following conclusions hold

(a) $\phi(x, y)=0$ if and only if $x=y$, for all $x, y \in X$;

(b) $\phi\left(x, \Pi_{D} y\right)+\phi\left(\Pi_{D} y, y\right) \leq \phi(x, y)$, for all $x \in D$, for all $y \in X$;

(c) if $x \in X$ and $z \in D$, then $z=\Pi_{D} x \Leftrightarrow\langle z-y, J x-J z\rangle \geq 0$, for all $y \in D$.

Remark 2.2. If $H$ is a real Hilbert space, then $\phi(x, y)=\|x-y\|^{2}$ and $\Pi_{D}$ is the metric projection $P_{D}$ of $H$ onto $D$.

Definition 2.3. A point $p \in D$ is said to be an asymptotic fixed point of $T: D \rightarrow \mathrm{CB}(D)$, if there exists a sequence $\left\{x_{n}\right\} \subset D$ such that $x_{n} \rightarrow x \in X$ and $d\left(x_{n}, T\left(x_{n}\right)\right) \rightarrow 0$. Denote the set of all asymptotic fixed points of $T$ by $\widehat{F}(T)$.

Definition 2.4. (1) A multivalued mapping $T: D \rightarrow \mathrm{CB}(D)$ is said to be relatively nonexpansive, if $F(T) \neq \emptyset, \widehat{F}(T)=F(T)$, and $\phi(p, z) \leq \phi(p, x)$, for all $x \in D, p \in F(T), z \in T(x)$.

(2) A multivalued mapping $T: D \rightarrow \mathrm{CB}(D)$ is said to be closed, if for any sequence $\left\{x_{n}\right\} \subset D$ with $x_{n} \rightarrow x \in D$ and $d\left(y, T\left(x_{n}\right)\right) \rightarrow 0$, then $d(y, T(x))=0$.

Next, we present an example of relatively nonexpansive multivalued mapping.

Example 2.5 (see [13]). Let $X$ be a smooth, strictly convex, and reflexive Banach space, let $D$ be a nonempty closed and convex subset of $X$, and let $f: D \times D \rightarrow R$ be a bifunction satisfying the conditions: (A1) $f(x, x)=0$, for all $x \in D$; (A2) $f(x, y)+f(y, x) \leq 0$, for all $x, y \in D$; (A3) $\lim _{t \rightarrow 0} f(t z+(1-t) x, y) \leq f(x, y)$, for each $x, y, z \in D$; (A4) the function $y \mapsto f(x, y)$ is convex and lower semicontinuous, for each $x \in D$. The "so-called" equilibrium problem for $f$ is to find a $x^{*} \in D$ such that $f\left(x^{*}, y\right) \geq 0$, for all $y \in D$. The set of its solutions is denoted by $\mathrm{EP}(f)$.

Let $r>0, x \in X$ and define mapping $T_{r}: X \rightarrow D$ as follows:

$$
T_{r}(x)=\left\{x \in D, f(z, y)+\frac{1}{r}\langle y-z, J z-J x\rangle \geq 0, \forall y \in D\right\}, \quad \forall x \in X
$$

then (1) $T_{r}$ is single-valued, and so $\{z\}=T_{r}(x)$; (2) $T_{r}$ is a relatively nonexpansive mapping, therefore it is a closed and quasi- $\phi$-nonexpansive mapping; (3) $F\left(T_{r}\right)=\mathrm{EP}(f)$.

Definition 2.6. (1) A multivalued mapping $T: D \rightarrow \mathrm{CB}(D)$ is said to be quasi- $\phi$-nonexpansive, if $F(T) \neq \emptyset$, and $\phi(p, z) \leq \phi(p, x)$, for all $x \in D, p \in F(T), z \in T(x)$. 
(2) A multivalued mapping $T: D \rightarrow \mathrm{CB}(D)$ is said to be quasi- $\phi$-asymptotically nonexpansive, if $F(T) \neq \emptyset$, and there exists a real sequence $k_{n} \subset[1,+\infty), k_{n} \rightarrow 1$ such that

$$
\phi\left(p, z_{n}\right) \leq k_{n} \phi(p, x), \quad \forall x \in D, p \in F(T), z_{n} \in T^{n}(x)
$$

(3) A multivalued mapping $T: D \rightarrow \mathrm{CB}(D)$ is said to be totally quasi- $\phi$-asymptotically nonexpansive, if $F(T) \neq \emptyset$, and there exist nonnegative real sequences $\left\{v_{n}\right\},\left\{\mu_{n}\right\}$ with $v_{n}$, $\mu_{n} \rightarrow 0($ as $n \rightarrow \infty)$ and a strictly increasing continuous function $\zeta: R^{+} \rightarrow R^{+}$with $\zeta(0)=0$ such that

$$
\phi\left(p, z_{n}\right) \leq \phi(p, x)+v_{n} \zeta[\phi(p, x)]+\mu_{n}, \quad \forall x \in D, \forall n \geq 1, p \in F(T), z_{n} \in T^{n}(x) .
$$

Remark 2.7. From the definitions, it is obvious that a relatively nonexpansive multivalued mapping is a quasi- $\phi$-nonexpansive multivalued mapping, and a quasi- $\phi$-nonexpansive multivalued mapping is a quasi- $\phi$-asymptotically nonexpansive multivalued mapping, but the converse is not true.

Lemma 2.8. Let $X$ be a real uniformly smooth and strictly convex Banach space with Kadec-Klee property, and let $D$ be a nonempty closed and convex subset of $X$. Let $\left\{x_{n}\right\}$ and $\left\{y_{n}\right\}$ be two sequences in $D$ such that $x_{n} \rightarrow p$ and $\phi\left(x_{n}, y_{n}\right) \rightarrow 0$, where $\phi$ is the function defined by (1.4), then $y_{n} \rightarrow p$.

Proof. For $\phi\left(x_{n}, y_{n}\right) \rightarrow 0$, we have $\left(\left\|x_{n}\right\|-\left\|y_{n}\right\|\right)^{2} \rightarrow 0$. This implies that $\left\|y_{n}\right\| \rightarrow\|p\|$ and so $\left\|J y_{n}\right\| \rightarrow\|J p\|$. Since $D$ is uniformly smooth, $X^{*}$ is reflexive and $J X=X^{*}$, therefore, there exist a subsequence $\left\{J y_{n_{i}}\right\} \subset\left\{J y_{n}\right\}$ and a point $x \in X$ such that $J y_{n_{i}} \rightarrow J x$. Because the norm $\|\cdot\|$ is weakly lower semi continuous, we have

$$
\begin{aligned}
0 & =\lim _{n_{i} \rightarrow \infty} \phi\left(x_{n_{i}}, y_{n_{i}}\right)=\lim _{n_{i} \rightarrow \infty}\left\{\left\|x_{n_{i}}\right\|^{2}-2\left\langle x_{n_{i}}, J y_{n_{i}}\right\rangle+\left\|J y_{n_{i}}\right\|^{2}\right\} \\
& \geq\|p\|^{2}-2\langle p, J x\rangle+\|J x\|^{2}=\phi(p, x) .
\end{aligned}
$$

By Lemma 2.1(a), we have $p=x$. Hence we have $J y_{n_{i}} \rightarrow J p$. Since $\left\|J y_{n_{i}}\right\| \rightarrow\|J p\|$ and $X^{*}$ has the Kadec-Klee property, we have $J y_{n_{i}} \rightarrow J p$. By Remark 1.1, it follows that $y_{n_{i}} \rightarrow p$. Since $\left\|J y_{n_{i}}\right\| \rightarrow\|J p\|$, by using the Kadec-Klee property of $X$, we get $y_{n_{i}} \rightarrow p$. If there exists another subsequence $\left\{J y_{n_{j}}\right\} \subset\left\{J y_{n}\right\}$ such that $y_{n_{j}} \rightarrow q$, then we have

$$
\begin{aligned}
0 & =\lim _{n_{j} \rightarrow \infty} \phi\left(x_{n_{j}}, y_{n_{j}}\right)=\lim _{n_{j} \rightarrow \infty}\left\{\left\|x_{n_{j}}\right\|^{2}-2\left\langle x_{n_{j}}, J y_{n_{j}}\right\rangle+\left\|J y_{n_{j}}\right\|^{2}\right\} \\
& =\|p\|^{2}-2\langle p, J q\rangle+\|q\|^{2}=\phi(p, q) .
\end{aligned}
$$

This implies that $p=q$. So $y_{n} \rightarrow p$. The conclusion of Lemma 2.8 is proved.

Lemma 2.9. Let $X$ and $D$ be as in Lemma 2.8. Let $T: D \rightarrow C B(D)$ be a closed and quasi- $\phi-$ asymptotically nonexpansive multivalued mapping with nonnegative real sequences $\left\{k_{n}\right\} \subset[1,+\infty)$, if $k_{n} \rightarrow 1$, then the fixed point set $F(T)$ of $T$ is a closed and convex subset of $D$. 
Proof. Let $\left\{x_{n}\right\}$ be a sequence in $F(T)$, such that $x_{n} \rightarrow x^{*}$. Since $T$ is quasi- $\phi$-asymptotically nonexpansive multivalued mapping, we have

$$
\phi\left(x_{n}, z\right) \leq k_{1} \phi\left(x_{n}, x^{*}\right)
$$

for all $z \in T x^{*}$ and for all $n \in N$. Therefore,

$$
\phi\left(x^{*}, z\right)=\lim _{n \rightarrow \infty} \phi\left(x_{n}, z\right) \leq \lim _{n \rightarrow \infty} k_{1} \phi\left(x_{n}, x^{*}\right)=k_{1} \phi\left(x^{*}, x^{*}\right)=0 .
$$

By Lemma 2.1, we obtain $z=x^{*}$, Hence, $T x^{*}=\left\{x^{*}\right\}$. So, we have $x^{*} \in F(T)$. This implies that $F(T)$ is closed.

Let $p, q \in F(T)$ and $t \in(0,1)$, and put $w=t p+(1-t) q$. we prove that $w \in F(T)$. Indeed, in view of the definition of $\phi$, let $z_{n} \in T^{n} w$, we have

$$
\begin{aligned}
\phi\left(w, z_{n}\right) & =\|w\|^{2}-2\left\langle w, J z_{n}\right\rangle+\left\|z_{n}\right\|^{2} \\
& =\|w\|^{2}-2\left\langle t p+(1-t) q, J z_{n}\right\rangle+\left\|z_{n}\right\|^{2} \\
& =\|w\|^{2}+t \phi\left(p, z_{n}\right)+(1-t) \phi\left(q, z_{n}\right)-t\|p\|^{2}-(1-t)\|q\|^{2} .
\end{aligned}
$$

Since

$$
\begin{aligned}
& t \phi\left(p, z_{n}\right)+(1-t) \phi\left(q, z_{n}\right) \\
& \leq t k_{n} \phi(p, w)+(1-t) k_{n} \phi(q, w) \\
&= t\left\{\|p\|^{2}-2\langle p, J w\rangle+\|w\|^{2}+\left(k_{n}-1\right) \phi(p, w)\right\} \\
&+(1-t)\left\{\|q\|^{2}-2\langle q, J w\rangle+\|w\|^{2}+\left(k_{n}-1\right) \phi(q, w)\right\} \\
&= t\|p\|^{2}+(1-t)\|q\|^{2}-\|w\|^{2}+t\left(k_{n}-1\right) \phi(p, w)+(1-t)\left(k_{n}-1\right) \phi(q, w) .
\end{aligned}
$$

Substituting (2.8) into (2.9) and simplifying it, we have

$$
\phi\left(w, z_{n}\right) \leq t\left(k_{n}-1\right) \phi(p, w)+(1-t)\left(k_{n}-1\right) \phi(q, w) \longrightarrow 0, \quad(\text { as } n \longrightarrow \infty) .
$$

Hence, we have $z_{n} \rightarrow w$. This implies that $z_{n+1}\left(\in T T^{n} w\right) \rightarrow w$. Since $T$ is closed, we have $T w=\{w\}$, that is, $w \in F(T)$. This completes the proof of Lemma 2.9.

Definition 2.10. A mapping $T: D \rightarrow \mathrm{CB}(D)$ is said to be uniformly $L$-Lipschitz continuous, if there exists a constant $L>0$ such that $\left\|x_{n}-y_{n}\right\| \leq L\|x-y\|$, where $x, y \in D, x_{n} \in T^{n} x$, $y_{n} \in T^{n} y$.

\section{Main Results}

Theorem 3.1. Let X be a real uniformly smooth and strictly convex Banach space with Kadec-Klee property, let $D$ be a nonempty, closed and convex subset of $X$, and let $T: D \rightarrow C B(D)$ be a closed and 
uniformly L-Lipschitz continuous quasi- $\phi$-asymptotically nonexpansive multivalued mapping with nonnegative real sequences $\left\{k_{n}\right\} \subset[1,+\infty)$ and $k_{n} \rightarrow 1$ satisfying condition (2.2). Let $\left\{\alpha_{n}\right\}$ be a sequence in $(0,1)$. If $\left\{x_{n}\right\}$ is the sequence generated by

$$
\begin{gathered}
x_{1} \in X \quad \text { is arbitrary; } D_{1}=D, \\
y_{n}=J^{-1}\left[\alpha_{n} J x_{1}+\left(1-\alpha_{n}\right) J z_{n}\right], \quad z_{n} \in T^{n} x_{n} \\
D_{n+1}=\left\{z \in D_{n}: \phi\left(z, y_{n}\right) \leq \alpha_{n} \phi\left(z, x_{1}\right)+\left(1-\alpha_{n}\right) \phi\left(z, x_{n}\right)+\xi_{n}\right\}, \\
x_{n+1}=\Pi_{D_{n+1}} x_{1} \quad(n=1,2, \ldots),
\end{gathered}
$$

where $\xi_{n}=\left(k_{n}-1\right) \sup _{p \in F(T)} \phi\left(p, x_{n}\right), F(T)$ is the fixed point set of $T$, and $\Pi_{D_{n+1}}$ is the generalized projection of $X$ onto $D_{n+1}$. If $F(T)$ is nonempty, then $\left\{x_{n}\right\}$ converges strongly to $\Pi_{F(T)} x_{1}$.

Proof. (I) First, we prove that $D_{n}$ are closed and convex subsets in $D$. By the assumption that $D_{1}=$ $D$ is closed and convex. Suppose that $D_{n}$ is closed and convex for some $n \geq 1$. In view of the definition of $\phi$, we have

$$
\begin{aligned}
& D_{n+1}=\left\{z \in D_{n}: \phi\left(z, y_{n}\right) \leq \alpha_{n} \phi\left(z, x_{1}\right)+\left(1-\alpha_{n}\right) \phi\left(z, x_{n}\right)+\xi_{n}\right\} \\
&=\left\{z \in D: \phi\left(z, y_{n}\right) \leq \alpha_{n} \phi\left(z, x_{1}\right)+\left(1-\alpha_{n}\right) \phi\left(z, x_{n}\right)+\xi_{n}\right\} \cap D_{n} \\
&=\left\{z \in D: 2 \alpha_{n}\left\langle z, J x_{1}\right\rangle+2\left(1-\alpha_{n}\right)\left\langle z, J x_{n}\right\rangle-2\left\langle z, J z_{n}\right\rangle\right. \\
&\left.\leq \alpha_{n}\left\|x_{1}\right\|^{2}+\left(1-\alpha_{n}\right)\left\|x_{n}\right\|^{2}-\left\|z_{n}\right\|^{2}\right\} \cap D_{n} .
\end{aligned}
$$

This shows that $D_{n+1}$ is closed and convex. The conclusions are proved.

(II) Next, we prove that $F(T) \subset D_{n}$, for all $n \geq 1$. In fact, it is obvious that $F(T) \subset D_{1}$. Suppose $F(T) \subset D_{n}$, for some $n \geq 1$. Hence, for any $u \in F(T) \subset D_{n}$, by (1.6), we have

$$
\begin{aligned}
\phi\left(u, y_{n}\right) & =\phi\left(u, J^{-1}\left(\alpha_{n} J x_{1}+\left(1-\alpha_{n}\right) J z_{n}\right)\right) \\
& \leq \alpha_{n} \phi\left(u, x_{1}\right)+\left(1-\alpha_{n}\right) \phi\left(u, z_{n}\right) \\
& \leq \alpha_{n} \phi\left(u, x_{1}\right)+\left(1-\alpha_{n}\right) k_{n} \phi\left(u, x_{n}\right) \\
& =\alpha_{n} \phi\left(u, x_{1}\right)+\left(1-\alpha_{n}\right)\left\{\phi\left(u, x_{n}\right)+\left(k_{n}-1\right) \phi\left(u, x_{n}\right)\right\} \\
& \leq \alpha_{n} \phi\left(u, x_{1}\right)+\left(1-\alpha_{n}\right)\left\{\phi\left(u, x_{n}\right)+\left(k_{n}-1\right) \sup _{u \in F(T)} \phi\left(u, x_{n}\right)\right\} \\
& =\alpha_{n} \phi\left(u, x_{1}\right)+\left(1-\alpha_{n}\right) \phi\left(u, x_{n}\right)+\xi_{n} .
\end{aligned}
$$

This shows that $u \in F(T) \subset D_{n+1}$ and so $F(T) \subset D_{n}$.

(III) Now, we prove that $\left\{x_{n}\right\}$ converges strongly to some point $p^{*}$. In fact, since $x_{n}=\Pi_{D_{n}} x_{1}$, from Lemma 2.1(c), we have

$$
\left\langle x_{n}-y_{,} J x_{1}-J x_{n}\right\rangle \geq 0, \quad \forall y \in D_{n} .
$$


Again since $F(T) \subset D_{n}$, we have

$$
\left\langle x_{n}-u, J x_{1}-J x_{n}\right\rangle \geq 0, \quad \forall u \in F(T)
$$

It follows from Lemma 2.1(b) that for each $u \in F(T)$ and for each $n \geq 1$,

$$
\phi\left(x_{n}, x_{1}\right)=\phi\left(\Pi_{D_{n}} x_{1}, x_{1}\right) \leq \phi\left(u, x_{1}\right)-\phi\left(u, x_{n}\right) \leq \phi\left(u, x_{1}\right)
$$

Therefore, $\left\{\phi\left(x_{n}, x_{1}\right)\right\}$ is bounded, and so is $\left\{x_{n}\right\}$. Since $x_{n}=\Pi_{D_{n}} x_{1}$ and $x_{n+1}=\Pi_{D_{n+1}} x_{1} \in$ $D_{n+1} \subset D_{n}$, we have $\phi\left(x_{n}, x_{1}\right) \leq \phi\left(x_{n+1}, x_{1}\right)$. This implies that $\left\{\phi\left(x_{n}, x_{1}\right)\right\}$ is nondecreasing. Hence $\lim _{n \rightarrow \infty} \phi\left(x_{n}, x_{1}\right)$ exists. Since $X$ is reflexive, there exists a subsequence $\left\{x_{n_{i}}\right\} \subset\left\{x_{n}\right\}$ such that $x_{n_{i}} \rightarrow p^{*}$ (some point in $D=D_{1}$ ). Since $D_{n}$ is closed and convex and $D_{n+1} \subset D_{n}$. This implies that $D_{n}$ is weakly closed and $p^{*} \in D_{n}$ for each $n \geq 1$. In view of $x_{n_{i}}=\Pi_{D_{n_{i}}} x_{1}$, we have

$$
\phi\left(x_{n_{i}}, x_{1}\right) \leq \phi\left(p^{*}, x_{1}\right), \quad \forall n_{i} \geq 1
$$

Since the norm $\|\cdot\|$ is weakly lower semicontinuous, we have

$$
\begin{aligned}
\lim _{n_{i} \rightarrow \infty} \inf \phi\left(x_{n}, x_{1}\right) & =\lim _{n_{i} \rightarrow \infty} \inf \left(\left\|x_{n_{i}}\right\|^{2}-2\left\langle x_{n_{i}}, J x_{1}\right\rangle+\left\|x_{1}\right\|^{2}\right) \\
& \geq\left\|p^{*}\right\|^{2}-2\left\langle p^{*}, J x_{1}\right\rangle+\left\|x_{1}\right\|^{2} \\
& =\phi\left(p^{*}, x_{1}\right)
\end{aligned}
$$

and so

$$
\phi\left(p^{*}, x_{1}\right) \leq \lim _{n_{i} \rightarrow \infty} \inf \phi\left(x_{n}, x_{1}\right) \leq \lim _{n_{i} \rightarrow \infty} \sup \phi\left(x_{n}, x_{1}\right)=\phi\left(p^{*}, x_{1}\right)
$$

This shows that $\lim _{n_{i} \rightarrow \infty} \phi\left(x_{n_{i}}, x_{1}\right)=\phi\left(p^{*}, x_{1}\right)$, and we have $\left\|x_{n_{i}}\right\| \rightarrow\left\|p^{*}\right\|$. Since $x_{n_{i}} \rightarrow p^{*}$, by the virtue of Kadec-Klee property of $X$, we obtain that $x_{n_{i}} \rightarrow p^{*}$. Since $\left\{\phi\left(x_{n}, x_{1}\right)\right\}$ is convergent, this together with $\lim _{n_{i} \rightarrow \infty} \phi\left(x_{n_{i}}, x_{1}\right)=\phi\left(p^{*}, x_{1}\right)$ shows that $\lim _{n_{i} \rightarrow \infty} \phi\left(x_{n}, x_{1}\right)=$ $\phi\left(p^{*}, x_{1}\right)$. If there exists some subsequence $\left\{x_{n_{j}}\right\} \subset\left\{x_{n}\right\}$ such that $x_{n} \rightarrow q$, then from Lemma 2.1, we have

$$
\begin{aligned}
\phi\left(p^{*}, q\right) & =\lim _{n_{i}, n_{j} \rightarrow \infty} \phi\left(x_{n_{i}}, x_{n_{j}}\right)=\lim _{n_{i}, n_{j} \rightarrow \infty} \phi\left(x_{n_{i}}, \Pi_{D_{n_{j}}} x_{1}\right) \\
& \leq \lim _{n_{i}, n_{j} \rightarrow \infty}\left[\phi\left(x_{n_{i}}, x_{1}\right)-\phi\left(\Pi_{D_{n_{j}}} x_{1}, x_{1}\right)\right]=\lim _{n_{i}, n_{j} \rightarrow \infty}\left[\phi\left(x_{n_{i}}, x_{1}\right)-\phi\left(x_{n_{j}}, x_{1}\right)\right] \\
& =\phi\left(p^{*}, x_{1}\right)-\phi\left(p^{*}, x_{1}\right)=0,
\end{aligned}
$$

that is, $p^{*}=q$ and hence

$$
x_{n} \longrightarrow p^{*} \text {. }
$$


By the way, from (3.11), it is easy to see that

$$
\xi_{n}=\left(k_{n}-1\right) \sup _{p \in F(T)} \phi\left(p, x_{n}\right) \longrightarrow 0 .
$$

(IV) Now, we prove that $p^{*} \in F(T)$. In fact, since $x_{n+1} \in D_{n+1}$, from (3.1), (3.11), and (3.12), we have

$$
\phi\left(x_{n+1}, y_{n}\right) \leq \alpha_{n} \phi\left(x_{n+1}, x_{1}\right)+\left(1-\alpha_{n}\right) \phi\left(x_{n+1}, x_{n}\right)+\xi_{n} \longrightarrow 0
$$

Since $x_{n} \rightarrow p^{*}$, it follows from (3.13) and Lemma 2.8 that

$$
y_{n} \longrightarrow p^{*}
$$

Since $\left\{x_{n}\right\}$ is bounded and $T$ is quasi- $\phi$-asymptotically nonexpansive multivalued mapping, $T^{n} x_{n}$ is bounded. In view of $\alpha_{n} \rightarrow 0$. Hence from (3.1), we have that

$$
\lim _{n \rightarrow \infty}\left\|J y_{n}-J z_{n}\right\|=\lim _{n \rightarrow \infty}\left\|J x_{1}-J z_{n}\right\|=0
$$

Since $J y_{n} \rightarrow J p^{*}$, this implies $J z_{n} \rightarrow J p^{*}$. From Remark 1.1, it yields that

$$
z_{n} \rightarrow p^{*}
$$

Again since

$$
\left\|z_{n}\right\|-\left\|p^{*}\right\|=\left\|J z_{n}\right\|-\left\|J p^{*}\right\| \leq\left\|J z_{n}-J p^{*}\right\| \longrightarrow 0,
$$

this together with (3.16) and the Kadec-Klee-property of X shows that

$$
z_{n} \longrightarrow p^{*}
$$

On the other hand, by the assumptions that $T$ is $L$-Lipschitz continuous, thus we have

$$
\begin{aligned}
d\left(T z_{n}, z_{n}\right) & \leq d\left(T z_{n}, z_{n+1}\right)+\left\|z_{n+1}-x_{n+1}\right\|+\left\|x_{n+1}-x_{n}\right\|+\left\|x_{n}-z_{n}\right\| \\
& \leq(L+1)\left\|x_{n+1}-x_{n}\right\|+\left\|z_{n+1}-x_{n+1}\right\|+\left\|x_{n}-z_{n}\right\| .
\end{aligned}
$$

From (3.18) and $x_{n} \rightarrow p^{*}$, we have that $d\left(T z_{n}, z_{n}\right) \rightarrow 0$. In view of the closeness of $T$, it yields that $T\left(p^{*}\right)=\left\{p^{*}\right\}$, this implies that $p^{*} \in F(T)$.

(V) Finally, we prove that $p^{*}=\Pi_{F(T)} x_{1}$ and so $x_{n} \rightarrow \Pi_{F(T)} x_{1}$. Let $w=\Pi_{F(T)} x_{1}$. Since $w \in F(T) \subset D_{n}$, we have $\phi\left(p^{*}, x_{1}\right) \leq \phi\left(w, x_{1}\right)$. This implies that

$$
\phi\left(p^{*}, x_{1}\right)=\lim _{n \rightarrow \infty} \phi\left(x_{n}, x_{1}\right) \leq \phi\left(w, x_{1}\right)
$$


which yields that $p^{*}=w=\Pi_{F(T)} x_{1}$. Therefore, $x_{n} \rightarrow \Pi_{F(T)} x_{1}$. This completes the proof of Theorem 3.1.

By Remark 2.7, the following corollaries are obtained.

Corollary 3.2. Let $X$ and $D$ be as in Theorem 3.1, and let $T: D \rightarrow C B(D)$ be a closed and uniformly L-Lipschitz continuous a relatively nonexpansive multivalued mapping. Let $\left\{\alpha_{n}\right\}$ in $(0,1)$ with $\lim _{n \rightarrow \infty} \alpha_{n}=0$. Let $\left\{x_{n}\right\}$ be the sequence generated by

$$
\begin{gathered}
x_{1} \in X \quad \text { is arbitrary; } \quad D_{1}=D, \\
y_{n}=J^{-1}\left[\alpha_{n} J x_{1}+\left(1-\alpha_{n}\right) J z_{n}\right], \quad z_{n} \in T x_{n}, \\
D_{n+1}=\left\{z \in D_{n}: \phi\left(z, y_{n}\right) \leq \alpha_{n} \phi\left(z, x_{1}\right)+\left(1-\alpha_{n}\right) \phi\left(z, x_{n}\right)\right\}, \\
x_{n+1}=\prod_{D_{n+1}} x_{1} \quad(n=1,2, \ldots),
\end{gathered}
$$

where $F(T)$ is the set of fixed points of $T$, and $\Pi_{D_{n+1}}$ is the generalized projection of $X$ onto $D_{n+1}$, then $\left\{x_{n}\right\}$ converges strongly to $\Pi_{F(T)} x_{1}$.

Corollary 3.3. Let $X$ and $D$ be as in Theorem 3.1, and let $T: D \rightarrow C B(D)$ be a closed and uniformly $L$-Lipschitz continuous quasi- $\phi$-nonexpansive multivalued mapping. Let $\left\{\alpha_{n}\right\}$ be a sequence of real numbers such that $\alpha_{n} \in(0,1)$ for all $n \in N$, and satisfying: $\lim _{n \rightarrow \infty} \alpha_{n}=0$. Let $\left\{x_{n}\right\}$ be the sequence generated by (3.21). Then, $\left\{x_{n}\right\}$ converges strongly to $\Pi_{F(T)} x_{1}$.

\section{Application}

We utilize Corollary 3.3 to study a modified Halpern iterative algorithm for a system of equilibrium problems.

Theorem 4.1. Let $D, X$, and $\left\{\alpha_{n}\right\}$ be the same as in Theorem 3.1. Let $f: D \times D \rightarrow R$ be a bifunction satisfying conditions (A1)-(A4) as given in Example 2.5. Let $T_{r}: X \rightarrow D$ be a mapping defined by (2.1), that is,

$$
T_{r}(x)=\left\{x \in D, f(z, y)+\frac{1}{r}\langle y-z, J z-J x\rangle \geq 0, \forall y \in D\right\}, \quad \forall x \in X
$$

Let $\left\{x_{n}\right\}$ be the sequence generated by

$$
\begin{gathered}
x_{1} \in X \quad \text { is arbitrary; } D_{1}=D, \\
f\left(u_{n}, y\right)+\frac{1}{r}\left\langle y-u_{n}, J u_{n}-J x_{n}\right\rangle \geq 0, \quad \forall y \in D, r>0, u_{n} \in T_{r} x_{n}, \\
y_{n}=J^{-1}\left[\alpha_{n} J x_{1}+\left(1-\alpha_{n}\right) J u_{n}\right], \\
D_{n+1}=\left\{z \in D_{n}: \phi\left(z, y_{n}\right) \leq \alpha_{n} \phi\left(z, x_{1}\right)+\left(1-\alpha_{n}\right) \phi\left(z, x_{n}\right)\right\}, \\
x_{n+1}=\Pi_{D_{n+1}} x_{1} \quad(n=1,2, \ldots) .
\end{gathered}
$$


If $F\left(T_{r}\right) \neq \emptyset$, then $\left\{x_{n}\right\}$ converges strongly to $\Pi_{F(T)} x_{1}$ which is a common solution of the system of equilibrium problems for $f$.

Proof. In Example 2.5, we have pointed out that $u_{n}=T_{r}\left(x_{n}\right), F\left(T_{r}\right)=\mathrm{EP}(f)$, and $T_{r}$ is a closed and quasi- $\phi$-nonexpansive mapping. Hence (4.2) can be rewritten as follows:

$$
\begin{gathered}
x_{1} \in X \quad \text { is arbitrary; } \quad D_{1}=D, \\
y_{n}=J^{-1}\left[\alpha_{n} J x_{1}+\left(1-\alpha_{n}\right) J u_{n}\right], \quad u_{n} \in T_{r} x_{n}, \\
D_{n+1}=\left\{z \in D_{n}: \phi\left(z, y_{n}\right) \leq \alpha_{n} \phi\left(z, x_{1}\right)+\left(1-\alpha_{n}\right) \phi\left(z, x_{n}\right)\right\}, \\
x_{n+1}=\Pi_{D_{n+1}} x_{1} \quad(n=1,2, \ldots) .
\end{gathered}
$$

Therefore the conclusion of Theorem 4.1 can be obtained from Corollary 3.3.

\section{References}

[1] I. Cioranescu, Geometry of Banach Spaces, Duality Mappings and Nonlinear Problems, vol. 62 of Mathematics and its Applications, Kluwer Academic Publishers, Dordrecht, The Netherlands, 1990.

[2] Y. I. Alber, "Metric and generalized projection operators in Banach spaces: properties and applications," in Theory and Applications of Nonlinear Operators of Accretive and Monotone Type, A. G. Kartosator, Ed., vol. 178 of Lecture Notes in Pure and Applied Mathematics, pp. 15-50, Marcel Dekker, New York, NY, USA, 1996.

[3] S. S. Chang, C. K. Chan, and H. W. J. Lee, "Modified block iterative algorithm for quasi- $\phi$-asymptotically nonexpansive mappings and equilibrium problem in Banach spaces," Applied Mathematics and Computation, vol. 217, no. 18, pp. 7520-7530, 2011.

[4] W. R. Mann, "Mean value methods in iteration," Proceedings of the American Mathematical Society, vol. 4, pp. 506-510, 1953.

[5] A. Genel and J. Lindenstrauss, "An example concerning fixed points," Israel Journal of Mathematics, vol. 22, no. 1, pp. 81-86, 1975.

[6] B. Halpern, "Fixed points of nonexpansive maps," Bulletin of the American Mathematical Society, vol. 73, pp. 957-961, 1967.

[7] K. Nakajo and W. Takahashi, "Strong convergence theorems for nonexpansive mappings and nonexpansive semigroups," Journal of Mathematical Analysis and Applications, vol. 279, no. 2, pp. 372-379, 2003.

[8] S. Y. Matsushita and W. Takahashi, "Weak and strong convergence theorems for relatively nonexpansive mappings in Banach spaces," Fixed Point Theory and Applications, vol. 2004, no. 1, pp. 37-47, 2004.

[9] S. Matsushita and W. Takahashi, "An iterative algorithm for relatively nonexpansive mappings by hybrid method and applications," in Proceedings of the 3rd International Conference on Nonlinear Analysis and Convex Analysis, pp. 305-313, 2004.

[10] S.-y. Matsushita and W. Takahashi, "A strong convergence theorem for relatively nonexpansive mappings in a Banach space," Journal of Approximation Theory, vol. 134, no. 2, pp. 257-266, 2005.

[11] X. Qin, Y. J. Cho, S. M. Kang, and H. Zhou, "Convergence of a modified Halpern-type iteration algorithm for quasi- $\phi$-nonexpansive mappings," Applied Mathematics Letters. An International Journal of Rapid Publication, vol. 22, no. 7, pp. 1051-1055, 2009.

[12] Z. Wang, Y. Su, D. Wang, and Y. Dong, "A modified Halpern-type iteration algorithm for a family of hemi-relatively nonexpansive mappings and systems of equilibrium problems in Banach spaces," Journal of Computational and Applied Mathematics, vol. 235, no. 8, pp. 2364-2371, 2011.

[13] E. Blum and W. Oettli, "From optimization and variational inequalities to equilibrium problems," The Mathematics Student, vol. 63, no. 1-4, pp. 123-145, 1994. 


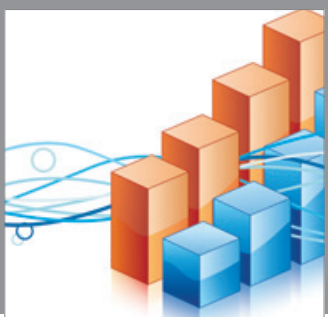

Advances in

Operations Research

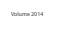

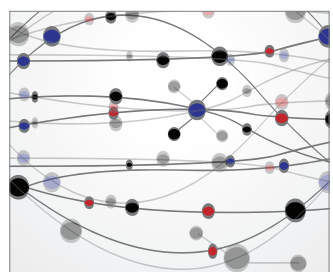

\section{The Scientific} World Journal
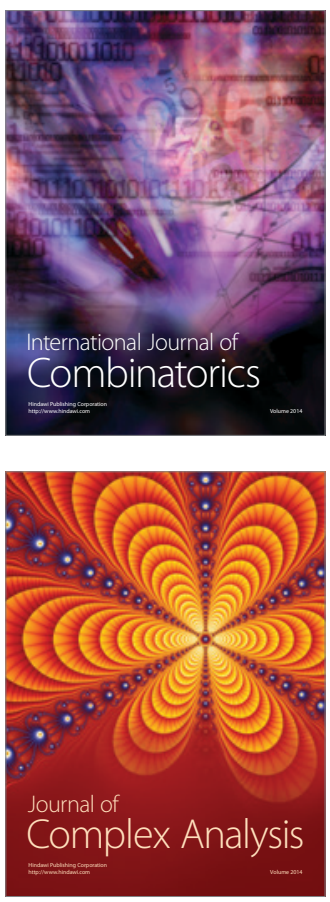

International Journal of

Mathematics and

Mathematical

Sciences
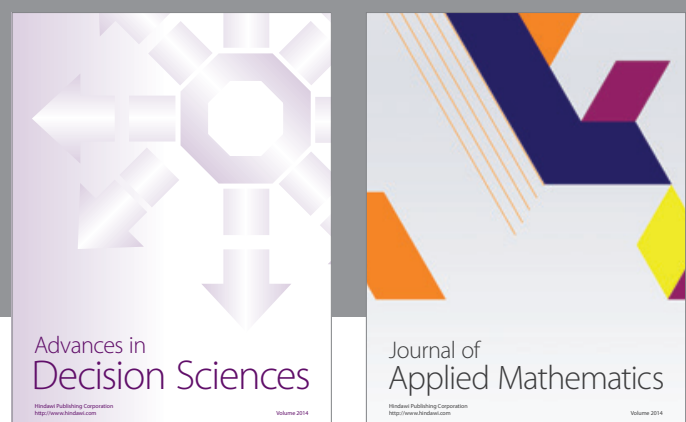

Journal of

Applied Mathematics
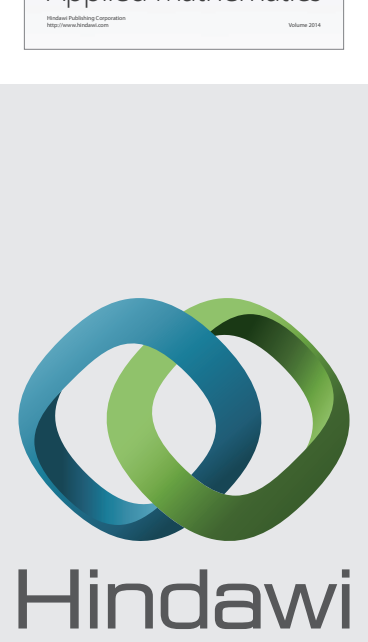

Submit your manuscripts at http://www.hindawi.com
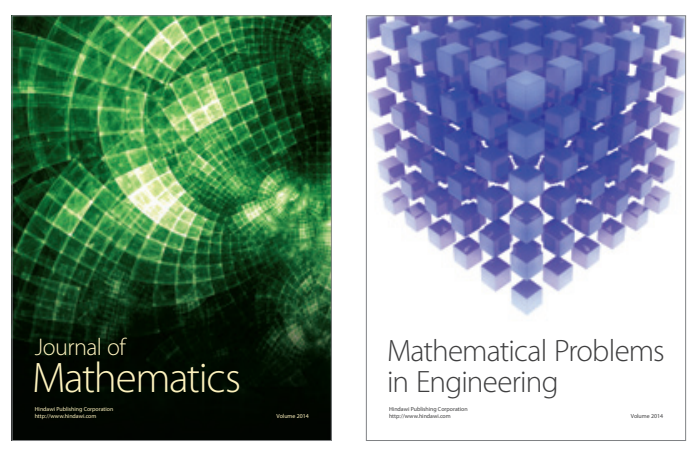

Mathematical Problems in Engineering
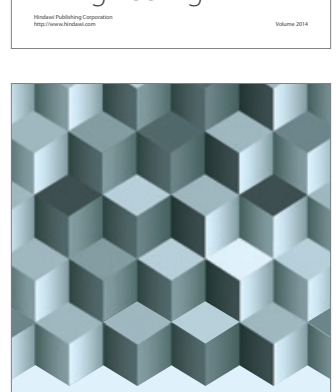

Journal of

Function Spaces
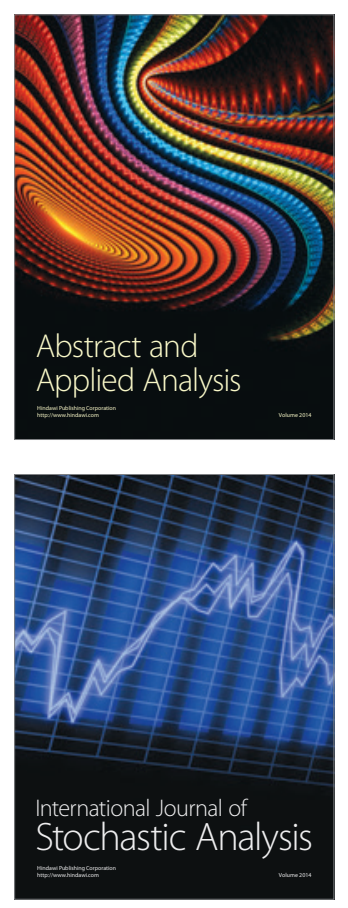

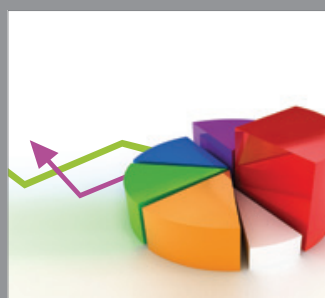

ournal of

Probability and Statistics

Promensencen
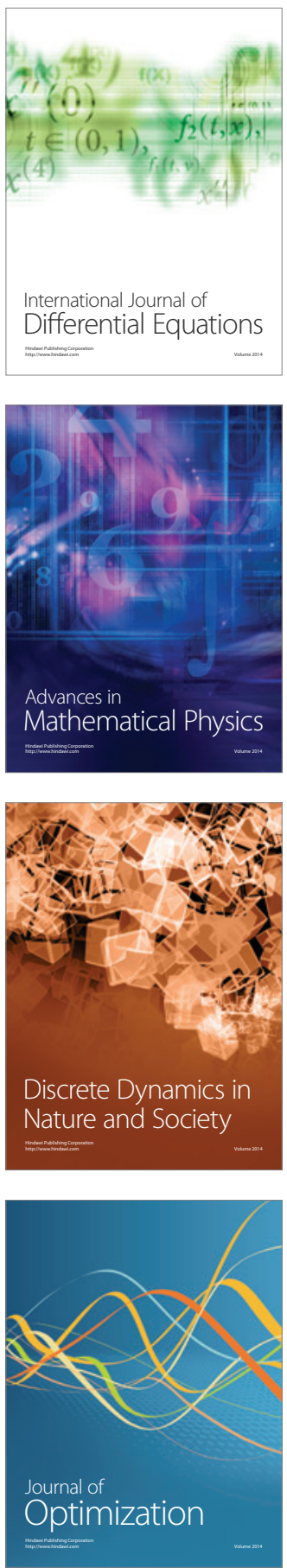